\title{
Positivist Research and its Influence in Management Accounting Research
}

\author{
Cheok Mui Yee and Edward Wong Sek Khin ${ }^{1}$
}

\begin{abstract}
This paper details the research process, which comprises epistemology, theoretical perspective and methodology. It provides an overall research process that discusses the epistemology of objectivism and theoretical perspective of positivism in management accounting research. There are many influences in management accounting research among which is positivism, even though it is considered as being under the direction of the sciences rather than the art of management. This epistemological anomaly and the methods used in management accounting research are not a simple problem that can be removed by the wave of a qualitative research magic wand to ignore the reality of quantitative evaluations in the management accounting field.
\end{abstract}

Keywords: epistemology, ontology, positive theory, ground theory, qualitative research

\section{Introduction}

\subsection{Research process}

The research process should be carefully planned and controlled so that the problem is investigated empirically. Chua (1986) further emphasized the need to clarify the process of research as different accounting schools of thought apply different perspectives of epistemology, theoretical position and methodology. Epistemology concerns the nature of knowledge, which then drives the theoretical perspective of the research and later determines the selection of the methodology or approach. By addressing these issues thoroughly, it is assured that knowledge and theoretical assumptions underlying this study are clearly explained and supported with justified research methodology so that the research findings are warranted. Particularly, this study adopts a predominantly objectivist epistemology, and, subsequently, a positivist theoretical perspective is used to select the appropriate research methodology.

\footnotetext{
Corresponding author: Dr Edward Wong Sek Khin is an Associate Professor at the Faculty of
} Business and Accountancy, University of Malaya, email: edwardwong@um.edu.my. 


\subsection{Epistemology}

Epistemology offers "a philosophical grounding for deciding what kinds of knowledge are possible and we can ensure that they are both adequate and legitimate" (Magnar et al., 1996). In other words, it is an approach to understanding how people know what they know. Objectivism, which adopted in this study, is one the main epistemological approaches that is used in mainstream accounting research as an alternative to constructivism and subjectivism. It posits that the meaningfulness of reality is independent of existence in that the world is external and objective. With such an argument, this study adopts an objectivepositivist approach to ensure the richness of information in quantitative results. Hence, the current study is built upon facts, causality, hypotheses formation and statistical testing.

\subsection{Theoretical perspective}

The theoretical perspective explains that in a positivist dimensions the philosophical stance informing the methodology and thus providing a context for the process and grounding its logic and criteria. It also signifies the overall conceptual framework or the "basic belief system or worldwide view that guides the investigation" (Guba \& Lincoln, 1994).

Sarantakos (1993) refers to the theoretical perspective as a paradigm. In this study, positivism is chosen as the theoretical perspective due to its ability to explain real world phenomena. Positivism has a highly objectivist view of a common and single reality. It holds that anything that can be perceived through senses is real and that reality is an externality that exists independently of human thought and perception. It is founded upon the ontological view that the 'reality' of accounting can be discovered by the use of senses or through sensory experience (empiricism), that accounting is objective, and that accounting hypotheses can be statistically tested to produce generalised findings. That is why Neuman (1997) viewed accounting as an organised method that integrates the logic of deduction with the observation of individual behaviour empirically in order to investigate and confirm a set of probable causal laws for the purpose of predicting general patterns of human activity.

Positivism uses quantitative data, surveys and statistics to provide a scientific explanation. It also offers a rigorous and objective measure for testing hypotheses. Empirical facts are assumed to exist apart from ideas and free from political, religious or personal values with an aura of disinterestedness and alleged objectivity. Such perspective is widely used within the scientific community. Based on this premise, this study takes on the view of positivism to explain the inter-relationship among ownership, empowerment and the voice of employees in influencing budgetary slack. 


\subsection{The aims of positivist research}

The aim of positivist research is to understand the fundamentals of science, leading to new scientific laws, propositions, and theories, based upon a given approach to reach a solution that is acceptable to other scientists in the same area of expertise. We are in an age of 'scientific management' a study that, over the decades, has not gained the support of the scientific community, because of the elusiveness of meeting the rigours of mathematical measurement.

As a result, in term of positivist perspective, the aim of research in management was to generate laws which will govern the operation of any organizations. This is to construct any management with these laws to become more scientific. Therefore, managers will become more predictive in their objective, functionality and unbiased political stand. Hence, social interactions were studied in the same way as physical elements. These elements in positivist approaches worked as a network of causal relations in the context of behaviour and stimulate people to behave in certain strategy. Thus, to elaborate this perspective, individual sense's making processes were being neglected, in order to be invalided and no result oriented

If what is observable is an objective reality, then researchers analysing this reality assume that the reality is objectively given, functionally necessary and politically neutral (Willmott, 1992; 1997). Empiricism deals with experiences that tend to be defined as generalization or causal descriptions through observations, which has led management research towards empiricism and marginalized theory in management research (Clegg and Dunkerley, 1980; Whitley, 1984).

There is a need to examine supporting data and logical causal suggestions in positivist management science. The importance of surveys and their design with experiments, supports the importance of empirical data as an evaluation of accepted or rejected theories based upon considered observable facts that describe relevant reality (Davis, 1985). This question of relevance is a source of argument in the positivist approach (Schon, 1995; Van Maanen, 1995), as Hogan and Sinclair dispute that positivist researchers identifying causal relationships narrow their focus until it lacks the ability to test the propositions examined. This means that the management theories that evolve from this type of research do not reflect upon the realities of the actions and dilemmas faced by managers every day.

\subsection{Research Methodology}

The research methodology describes a plan of action or design behind the selection of a particular research method and how to link them towards desired outcomes. Different approaches will be applied depending upon the underlying epistemology stance taken. In this study, the survey approach will be adopted as the methodology to gather relevant data from the sample. The logical reasoning behind the adoption of such a technique is to ensure the richness of information 
gathered so that the researcher can better understand the results analysed from the statistical approach.

Hence, positivism, as a research methodology, expects quantitative analyses of various types, as numbers show the research conclusions based upon certain mathematical processes. In general, mathematics is truth writ large, and can withstand attacks upon its conclusions if the uses of proven mathematical processes are shown.

Qualitative analyses, however, are being accepted more and more as a basis for valid and true conclusions, and these conclusions have been brought about by using logical processes, and while positivists may underestimate the value of qualitative analyses, they are no longer underestimated as they have been historically.

However, from the nineteenth-century, interpretations using rigorous quantitative methods have been developed to high levels of sophistication and ask similar questions as qualitative analyses while offering mathematical and scientifically valid conclusions that qualitative methods must use language to describe. There are serious questions that any language is adequate for all questions. There is no other response than that mathematics should fill the gaps that language cannot, and this is found in the movement towards more rigorous quantitative research (Marsh, 1979; Pfeffer, 1995).

The disputes between these two approaches, at times, are broad and growing, as the diversity of acceptance of a conclusion, using whatever methodology is arguable, depending upon which side one takes. However, positivism still holds its dominant position, even when dealing with the workings of organizations.

Johnson and Duberley discussed not the disputes between these two methods but the commonalities of both social and natural science. Natural science is the basis of using the experimental methods of natural science in a social science situation, particularly in cause and effect investigations.

Part of the research in the social sciences is the adoption of experimental design, a combination of random choice and control groups, the positivist's classical experimental design is one that yields high levels of internal validity. Within this approach, Aronson and Carlsmith (1986) enquired as to the necessity of experimental realism coupled with mundane realism, that which surrounds the experiment, which may be as important as or more important than the experiment itself. One may look no further than the Hawthorne Experiment to illustrate this point.

Campbell and Stanley (1963) developed another approach of quasiexperimentation to develop analyses in the field.

Surveys generally supply correlations and not the cause at a particular point in time, but remain a mainstay of positivist social science research. The process is a systematic collection of quantifiable data to establish a relationship among variables to show patterns of association (Bryman, 1992). 


\section{Preoccupation of positivism research}

\subsection{Causality or internal validity}

For positivism to work there must be a case of a cause of a problem or perceived situation, this is called causality or internal validity, and where there must be some independent factor that leads to a distinct outcome called the dependent variable. However, there are risks to this approach, as other extraneous factors have the ability to pose risks to this process. Cook and Campbell list twelve such threats: (1) history, (2) testing, (3) instrumentation, (4) regression, (5) mortality, (6) maturation, (7) selection, (8) selection by maturation interaction, (9) ambiguity about causal direction, (10) diffusion of treatments, (11) compensatory equalization of treatments, and (12) compensatory rivalry.

To control the research environment the researcher either has tight controls over the causal links or internal validity or uses survey methodologies. The survey allows an interpersonal relationship confined to the limitations of a randomly selected survey process and if followed by interviews allows reinforcement of the survey results. However, this process is not perfect, as what the researcher possesses is a series of responses that may have little relation to the researcher's needs, and causation may not be discovered or verifiable. Miller and Friesen (1984), and Schoonhoven (1981) used the example of the extensive criticism of the contingency approach to organizational design that uses this method.

\subsection{Reliability and replication}

Reliability means assurance that what is described as the cause, is the cause of the effect researched. Unless a measure is reliable, it cannot be valid (Schriesheim et al., 1993), and, hence, the threats to reliability identified by Whitley (1984) make the researcher use care in ensuring reliability. These threats are subject error, subject bias, observer error, and observer bias. Truth is a beauty of many guises, and when dealing with the descriptions of objective measures of organizational trends, most texts describe the necessity of these measures because of perceived and real bias. This is particularly noticeable in the completion of even simple questionnaires (Silverman, 1993).

What is left is replication of established findings supporting a given research project that eliminates bias and ensures reliability.

\subsection{Generalizability}

Generalizability is a problem for both experimental and survey research. Surveys suffer from the age old problem of timing, the manner of the survey, the place of the survey and its topic, and the attitude of the participants towards surveys in general. Le Compte and Goetz have highlighted the threats as selection, setting, history and construct effects. Clearly, there are solutions to these problems, the main one being having a fully representative population and then probability 
sampling for survey participants. This process will then allow the possibility of using statistical inference to describe the population from a well-structured sample survey, and thereby give a good representation of the population.

\subsection{Operationalism}

Operationalism is the process of direct observation and using that representation to describe that which can only be indirectly observed, and is typically used in describing emotive topics, such as motivation. Observation is the key to this type of research, and, in these cases, the research uses indicators to represent concepts, or, as termed by Moser and Kalton (Marsh, 1979), the 'individual true value', Precision of measurement, however, depends upon the specification of what concepts mean and precisely how they will be measured.

Clegg and Dunkerley (1980) have shown that by using scaling and measurement techniques, the descriptions of operationalizing organizations can objectify these organizations, leading to the conclusion that any concept is reduced to a scale of observable indicators.

Validity is concerned with the extent to which the measurement provides an accurate reflection of the concept, and validity within operationalization is vital to the conclusions reached. One way of doing this is to compare similar or the same operationalization with others. Assuming that an objective reality is measured, using the same measurements and techniques, then we expect the same findings.

Sometimes this does not occur. An example is the Aston Studies, where various approaches were used to examine Aston's structure and the agreement among them was disappointing. Hence, the important of operationalize a concepts will impact the validity of the study. In this sense validity is concerned with the extent to which the measurement provides an accurate reflection of the concept. By comparing the operationalizations the same concepts with similar study, researchers should be able to ensure how valid is the constructs been measure in difference dimension.

\section{Conclusions}

Positivism is not mainstream in management accounting research because, "much of what is considered positivistic management research may not actually represent positivism as it remains under-theorized and conceptually lacking, thus perhaps being better described as naive empiricism'.

Researchers also 'challenge the assumption that a positivist approach equates with the use of quantitative methods and that therefore those adopting qualitative methods are necessarily anti-positivist'. They 'argue that the relationship between epistemology and method should not be summary to a basic "quantitative versus qualitative" debate'. 


\section{References}

Aronson, E; Carlsmith, J.M. (1986) Experimentation in social psychology, in G. Lindzey and E. Aronson (eds), Handbook of Social Psychology. Reading, MA.: Addison Wesley.

Bryman, A. (1992) Research Methods and Organisational Studies. London: Routledge.

Campbell, D.T; Stanley, J.C. (1963) Experimental and Quasi-Experimental Designs for Research. Chicago: Rand McNally

Chua, W. F. (1986). Radical developments in accounting thought. Accounting Review, 61(4), 601-632.

Clegg, S. and Dunkerley, D. (1980) Organisation Class and Control. London: Routledge and Kegan Paul.

Davis, J. (1985) The Logic of Causal Order. Beverly Hills, CA: Sage.

Guba, E. G, \& Lincoln, Y. S. (1994). Competing paradigms in qualitative research. Handbook of Qualitative Research, 2, 163-194.

Magner, N; Welker, R. B; Campbell, T. L. (1996). Testing a model of cognitive budgetary participation processes in a latent variable structural equations framework. Accounting and Business Research, 27(1), 41-50.

Marsh, C (1979) Problems with surveys: method or epistemology, Sociology, 13 (2): 293-305.

Miller, D ; Friesen, P. (1984) Organisations :A Quantum View. Englewood Cliffs, NJ: Prentice Hall.

Moser, C.A. and Kalton, G. (1971) Survey Methods in Social Investigation. Aldershot: Gower.

Neuman, L. (1997). Social Research Methods: Qualitative and Quantitative Approaches ( $4^{\text {th }}$ eds.) New York, NY: Allyn and Bacon.

Pfeffer, J. (1995) Mortality, reproducibility and the persistence of styles of theory, Organisation Science, 6 (6): 681-93.

Sarantakos, S. (1993). Social research. South Melbourne, AUS: MacMillan

Schon, D.A. (1983) The Reflective Practitioner: How Professionals Think in Action. London: Temple Smith.

Schoonhoven, C.B. (1981) 'Problems with contingency theory: testing assumptions hidden within the language of contingency theory', Administrative Science Quarterly, 26: 349-77.

Schriesheim, C., Powers, K; Scandura, T., Gardiner, C; Lankall, M. (1993) 'Improving construct measurement in management research: comments and a quantitative approach for assessing the theoretical content adequacy of paper and pencil type survey instruments', Journal of Management, 19 (2): 385-417.

Silverman, D. (1993) Interpreting Qualitative Data. London: Sage.

Van Maanen, J. (1995a) An end to innocence: the ethnography of ethnography, in J. Van Maanen, Representation in Ethnography. London: Sage. 
Whitley, R.D. (1984) The scientific status of management research as a practically oriented social science, Journal of Management Studies, 21 (4): 369-90.

Willmott, H. (1992) Beyond paradigmatic closure in organisational enquiry, in J. Hassard and D. Pym, The Theory and Philosophy of Organisations. London: Routledge.

Willmott, H. (1997) Rethinking management and managerial work: capitalism, control and subjectivity, Human Relations, 50 (11): 1329-59. 